\title{
Effects of the Practice of Team Sport or Individual Sport on Perceptual Abilities and on the Self-Esteem in the Persons with Motor Disability: A Comparative Study
}

\author{
Saber Hamrouni', Said Ben Hassen'1, Kaabi Sofiene ${ }^{2}$, Sofiene Lagha', Jaouad Alem ${ }^{3}$ \\ ${ }^{1}$ High Institute of Sport and Physical Education, Manouba University, Manouba, Tunisia \\ ${ }^{2}$ Laboratoire Mouvement, Equilibre, Performance, Santé (MEPS), Département of STAPS, Université de Pau et des Pays de \\ l'Adour, Tarbes, France \\ ${ }^{3}$ Sciences and Physical Activities' School, Laurentian University, Sudbury, Canada \\ Email: haltero99@hotmail.fr
}

How to cite this paper: Hamrouni, S., Hassen, S. B., Sofiene, K., Lagha, S., \& Alem, J. (2017). Effects of the Practice of Team Sport or Individual Sport on Perceptual Abilities and on the Self-Esteem in the Persons with Motor Disability: A Comparative Study. $A d$ vances in Physical Education, 7, 319-331. https://doi.org/10.4236/ape.2017.73026

Received: September 27, 2016

Accepted: August 15, 2017

Published: August 18, 2017

Copyright $\odot 2017$ by authors and Scientific Research Publishing Inc. This work is licensed under the Creative Commons Attribution International License (CC BY 4.0).

http://creativecommons.org/licenses/by/4.0/

CC) (i) Open Access

\begin{abstract}
Our study comes in keeping with the impetus of the works that brought out the significant effects of the APSA practice on the global self-esteem and on the perceived physical value by the Spinal and Cord injured (Dias, Gerrnigon, $\&$ Ninot, 2009). It proposes, in a comparative perspective, to assess the effect of the practice of an individual sport versus a team sport on auditory, temporal, spatial and perceptual abilities as well as on the self-esteem in motor disabled persons. In other words, can these perceptual abilities and the self-esteem be regarded as acquirable skills among the motor disabled? The sample of our study consists of 112 able-bodied and tetraplegic subjects, and all of them are males, aged $18-24$ years $(M=19.97)$ and divided into 5 groups: 4 experimental groups (N1: 18 motor disabled basketball players; N2: 23 motor disabled athletes; N3: 20 able-bodied basketball players; and N4: 20 able-bodied athletes) and a sample group $(\mathrm{NT}=31) .3$ tests measured the auditory perception (Legent, Bordure, Calais, \& Malard, 2002), the time perception (Parlebas, 1986) and finally the space perception (Nyabenda, Briart, Deggouj, \& Gersdorff, 2003). As for the self-esteem, it was measured by a PSD Questionnaire (Marsh \& Yeung, 1998). It appears that the practice of team sport contributes more to the development of the auditory perception among the motor disabled persons. The difference between groups of motor disabled basketball players and motor disabled athletes was very significant. Test results in the perception of time and distance show a significant difference in favour of the motor disabled practitioners compared to the motor disabled practitioners. Moreover, the practice of a team or of an individual sport contributes more efficiently to
\end{abstract}


the development of these two perceptual abilities, especially in the athletes with motor disability. Finally, the self-esteem is higher among the basketball players with motor disability. This study proposes an interesting hypothesis action to the sport interveners since it demonstrates that the practice of sport, as a socio-motor game, contributes to a better development of the self-esteem than as a psychomotor game among subjects with motor disability.

\section{Keywords}

Auditory Perception, Time Perception, Space Perception, Self-Esteem, Motor Disability

\section{Introduction}

Our study aimed to assess the effect of the practice of a team sport such as basketball on auditory and visual perceptual abilities as well as on the self-esteem among the persons with motor disability. The self-esteem is a generic term for self-perception (Fox \& Corbin, 1989) and can be considered as a universal concept encompassing the able-bodied and the disabled persons.

It's found that all areas require physical and mental skills. The idea that there is a close relationship between the body image and the sport activity was sustained by Lhermite (1998). The practice of motor activities for an able-bodied individual or for a motor disabled individual is a good method to improve one's subjective wellbeing.

According to Bilard (1995), the self-esteem of a motor disabled individual could be affected when he compares himself to able-bodied subjects. The practice of adapted physical activities (APA) can promote the self-esteem reconstruction through possible motor-success experiences (Blayak \& Barbi, 2001). On the other hand, works have been able to reveal significant effects of the practice of adapted physical activity on the overall self-esteem and on the physical value perceived by the medullar injured (Dias, Gerrnigon, \& Ninot, 2009).

As for the non-practitioners with motor disability, they are in possession of goals of avoidance-mastership that are better marked than in the case of their practicing counterparts (Schiano-Lomoriello, Cury, \& Dafonseca, 2005).

Moreover, the influence of the adapted physical activities is more or less important depending on the practiced sport and on the level of the practice. Space, time, the number of the practitioners, the location of the coach as well as that of the practitioner himself and the role or the task of the practitioner may be determined in the transmission of the efferent or afferent information. Filtering, selection and organization of the information represent the major point of difference of a disabled or able-bodied athlete that may be characterized by good perceptive qualities, lying in a network of exchange and encoding (veral, gestural and practical) and the rest of his partners (Parlebas, 1986).

According to Bandura (2003), the system of beliefs that form the sense of 
personal efficiency feeling is the basis of the motivation and the action and thus of human achievement and wellbeing. Indeed, for everyone, there would be thousands of possibilities and challenges that are likely to foster one's self-development through the optimal experience (Csikszentmihalyi, 2004: p.24). This experience or flow state usually comes forward when there is a balance between the personal abilities and the task request no matter whether the subject is a disabled or an able bodied person.

In consideration of those conclusions, we may aim to:

- Assess the existing relationships between the types of practiced sport (individual versus team sport). It's about to check if the types of practiced sport (individual versus team sport) is likely to develop differently those qualities.

- Check whether the development of the auditory, space and time abilities in the persons with motor disability is tributary of the importance of the playing space, the issue or of the internal logic of the sport discipline that seeks an important spatial moving.

- Check whether the sport disciplines embracing a bigger number of contestants (partners and opponents) may be pleasing to develop the self-esteem in the person with motor disability.

\section{Methods}

In order to answer to the different questions of our research, we appealed to a sample of $\mathrm{N}=112$ Tunisian male subjects consisting of able bodied and tetraplegic persons with one or two amputated lower limbs, aged between 18 and 24 years ( $\mathrm{MA}=19.97)$ and with an average sport practice of $\mathrm{M}=4.39$ years. The sporting experience plays an important part in the structuring of time and space capacity.

Our sample was divided into 5 groups: 4 experimental and a control group. The experimental groups are divided as follow:

$\mathrm{N} 1=18$ motor disabled basketball players or basket-ball players on wheelchair;

$\mathrm{N} 2=23$ motor disabled athletes;

N3 $=20$ able bodied basketball players;

N4 $=20$ able bodied athletes; and

$\mathrm{NT}=31$ a control group consisting of non-practicing motor disabled.

\subsection{Evaluation Tools}

\subsubsection{Auditory Perception Test}

This test is inspired by the works of Legent, Bordure, Calais and Malard (2002). It consists of determining the auditory perception among the practitioners of different sport disciplines establishing a discrimination percentage (or maximum score of vocal recognition). This discrimination percentage reveals the auditory acuteness and through that the ear selectivity. It is indeed a percentage of words included at the most comfortable level for the subject. This level is usually situated between 30 and $40 \mathrm{Db}$ above the edge of intelligibility. In our test, we pronounced about twenty phonetically balanced words and we carefully varied 
them in order to avoid any familiarization. We began by asking the subjects about the degree of comfort of the chosen level and whether it was better to alter it. The result of the test was given in percentage of identified and obtained words at an intensity level superior to 5 or $10 \mathrm{Db}$, according to the desired comfort. The test took place with the subjects being blindfolded, inside approximate surface of $80 \mathrm{~m}^{2}$. This used to be the average surface for the motor action to all subjects in order to test also their auditory orientation.

Located in the center of a circle, and after having completed 5 laps around himself, the subject has to detect the source of the auditory stimuli (witch assess the orientation) coming from one of the 8 partners positioned at the periphery and has to identify the spoken words (assessing discrimination).

\subsubsection{Test of Time Perception}

This test is inspired by the thesis Jonveaux (2010) and it consists of determining the level of time perception among the practitioners of different sport disciplines. Without visual check, the subject tries to determine a lapse of time of 20 seconds 3 times during one minute. The difference between the real time and the perceived time is recorded. The choice of the 20 seconds length is justified by the fact that in basketball, the average length of the attack for both able bodied and motor disabled should not exceed 24 seconds. Our athletes, bodied and disabled are runners of 100 meters. The average duration of $100 \mathrm{~m}$ course is $11.5 \mathrm{~s}$ for valid subjects and $20.5 \mathrm{~s}$ for the disabled. The average length of the $100 \mathrm{~m}$ race and the duration of the basketball attack are about 20 seconds. The measurement of the test is the average of the 3 estimates of 30 seconds. The greater the gap, the more it is question of over or under estimation.

\subsubsection{The Test of Spatial Perception}

It's a about a test that determines the level of space perception among the athletes. Without visual control, the subject tries to walk for a distance of 10 meters (Nyabenda, Briart, Deggouj, \& Gersdorf, 2003). The subject is asked to perceive a distance of 10 meters, and then in the absence of any visual control, he is reminded to walk the same distance. The difference between the real distances travelled blindfolded and the perceived distance (declared) is finally recorded. The pass criterion consists of a reduced gap between the perceived and the real.

\subsubsection{The Questionnaire PSDQ Physical Self-Description Questionnaire} (Marsh \& Yeung, 1998)

The PSDQ contains a wide range of skill levels, appearance, ability, participation or physical satisfaction. More specifically; it assesses self-perceptions through nine specific dimensions: health, coordination, physical activity, adiposity, athletic skills, physical appearance, strength, flexibility, endurance as well as those of the two global evaluative components which are global physical satisfaction and global self-esteem.

Nine of the eleven subscales consist of six items whereas health and self-es- 
teem have eight. The response format is a type of six points scale. The theoretical framework and the instructions are in the recommendations of the testing manual. Comparative structural analyses involving several other physical self-concept instruments have demonstrated excellent psychometric properties. The alpha reliability coefficients are relatively high for all scales $(\mathrm{Md}=91)$. The coefficients of test-retest stability for all scales are satisfactory over the short term and the long term ( $\mathrm{Md}=0,83$ for 3 months and 0,69 for 14 months). The confirmatory factor analyses have clearly identified each one the eleven factors. The external validation of the test was currently carried out in a battery of fitness tests (Marsh \& Yeung, 1998).

\subsection{Statistical Analysis}

To compare the performances to the perceptive tests, we used the single factor Anova. For the purpose of the PSDQ analysis, we opted for The Khi-Square which is a statistical procedure for comparing the group members or the frequencies.

\section{Results}

This section presents the comparison of different variables like auditory perception, time and space perception and finally self-esteem perception. For the different variables in study, we performed multiple comparisons through Tukey's test at a confidence interval of $95 \%$.

\subsection{Auditory Perception}

The test results of auditory perception demonstrate superiority of physically disabled basketball players compared to disabled and able-bodied athlete (significant difference of $P>.05$ ). These results also show the superiority of the disabled non-athlete compared to the motor-disabled athletes.

According to the data of this Table 1, it appears that auditory orientation is better among athletes playing basketball. It also appears that sport as a team game contributes to the development of the auditory perception in the athletes.

\subsection{Time Perception}

Estimates of the time (20 seconds) of the able-bodied basketball players are better than those of the disabled non-athlete (significant difference of $P>.05$ ).

Table 1. Percentages of auditory orientation.

\begin{tabular}{cc}
\hline Motor disabled basketball players & $98 \%$ \\
Motor disabled athletes & $95 \%$ \\
Able bodied basketball players & $98 \%$ \\
Able bodied athletes & $96 \%$ \\
Non-practitioners & $91 \%$ \\
\hline
\end{tabular}


The test results related to time perception show that, in general, sport contributes effectively to the development of the perception of time especially among the able bodied and the motor-disabled basketball players.

\subsection{Spatial Perception (Distance)}

Disabled basketball players, Disabled athletes, able bodied basketball players, able bodied athletes, and Disabled non-practitioners.

The estimates of the distance ( 10 meters) of the able-bodied basketball players are better than those of the disabled basketball players, then the motor-disabled athletes as well as the disabled non-practitioners. On the other hand, the estimates of the motor-disabled basketball players are better than those of the disabled non-practitioners. The estimates of the able bodied athletes are also better than those of the motor-disabled athletes. And, finally, the estimates of the able-bodied athletes are more effective than those of the disabled non-practitioners. All these differences are significant at $P>.05$.

We can therefore conclude that the practice of sport like basketball on wheelchair develops efficiently the perception of distances among the motor-disabled subjects.

\subsection{The Physical Self-Esteem}

By sparingly statistical analysis, we didn't opt for multiple comparisons. Only one comparison, the most relevant was therefore retained. It was in this case the comparison between the basketball players and the athletes with motor disabilities.

The 11 scores of the PSDQ subscales are calculated by averaging the responses to the items designed to measure each scale (the numbers of the items are placed in brackets and follow the name of each scale) after reversing the scores for the negatively formulated items (marked by the sign (-)).

An analysis of the questionnaire results (PSDQ) enables us to notice in a quite remarkable way a general trend towards a better physical self-esteem, in the motor-disabled basketball players at all subscales. This self-esteem is significantly better in the motor-disabled basketball players and it is located in the sub-scales: health ( $\left.\mathrm{ddl}=7, \mathrm{Kh}^{2}=17.86, P<.05\right)$, adiposity $\left(\mathrm{ddl}=5, \mathrm{Kh}^{2}=15.51\right.$, $P<.010$ ), coordination ( $\mathrm{ddl}=5, \mathrm{Kh}^{2}=19.49, P<.010$ ), global physical satisfaction $\left(\mathrm{ddl}=5, \mathrm{Kh}^{2}=15.51, P<.05\right)$, global self-esteem $\left(\mathrm{dl}=7, \mathrm{Kh}^{2}=15.95, P\right.$ $<.05)$ and sporting competence $\left(\mathrm{ddl}=5, \mathrm{Kh}^{2}=14.03, P<.03\right.$ ) (cf. the subscales endowed with asterisks).

Nevertheless, no significant difference was noticed at the subscales: strength, flexibility, endurance, physical activity and physical appearance.

\section{Discussion}

The results of the auditory perception test, having demonstrated the superiority of the motor-disabled basketball players com-pared to the disabled and able-bodied athletes, enable us to affirm that team sports develop better the auditory per- 
ception (Significant difference at $P>.05$ ) (Figure 1). Furthermore; the superiority of the non-athlete disabled, compared to the motor-disabled athletes could be explained by the transfer of the senses enjoyed by the disabled people, in general way to compensate for certain deficiencies (Table 1).

Regarding the time perception, the results show that, in general, practicing sport contributes effectively to the development of time perception, especially in ablebodied and disabled basketball players (Figure 2).

Regarding the perception of distance (10 meters), the estimates of the ablebodied basketball players are better than those of the disabled basketball players, than the motor disabled athletes as well as the non-athlete disabled. Finally, the estimates of the able-bodied athletes are better than those of the motor-disabled athletes. On the other hand, the estimates of the able bodied athletes are still better than those of the non-athlete disabled (Figure 3) (Significant differences at $P>.05)$.

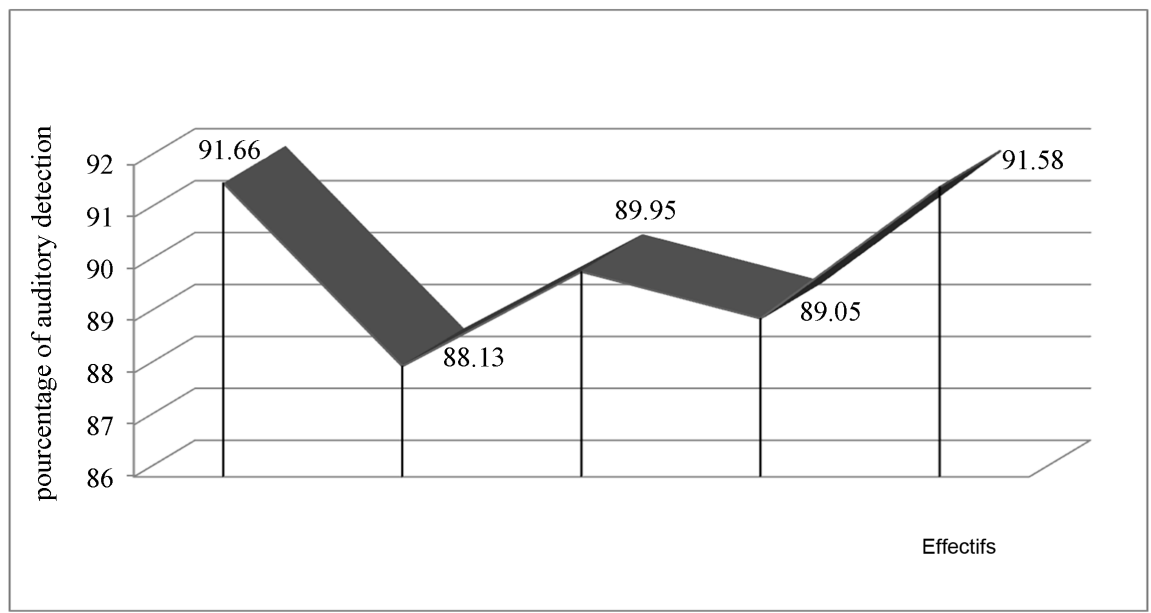

Figure 1. Auditory discrimination percentage. The test results of auditory perception demonstrate superiority of physically disabled basketball players compared to disabled and ablebodied athlete (significant difference of $P>.05$ ). These results also show the superiority of the disabled non-athlete compared to the motor-disabled athletes.

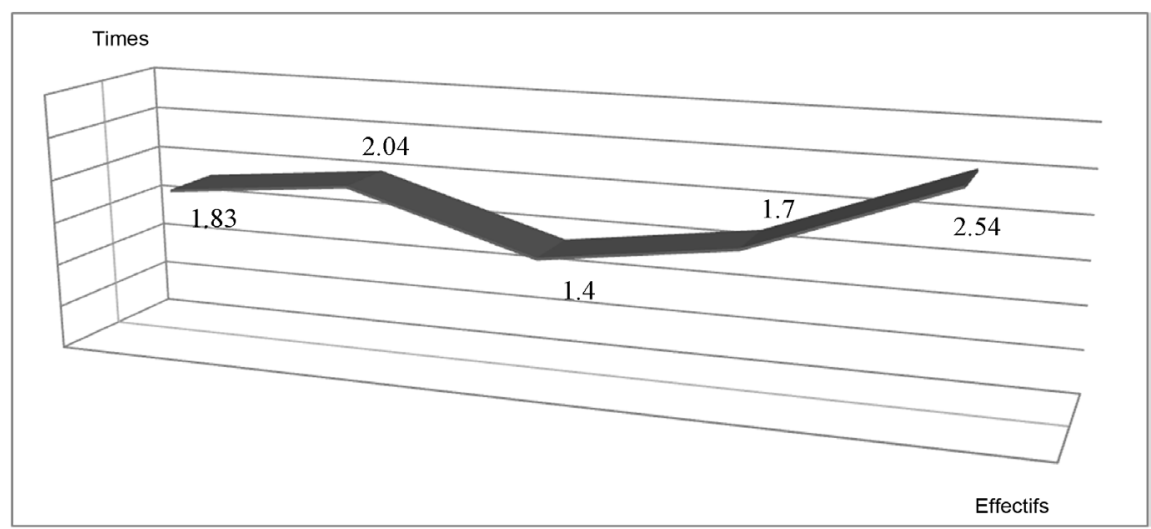

Figure 2. Average variation of the time estimates (20 seconds). $1.83=$ Disabled basketball players; $2.04=$ Disabled athletes; $1.4=$ Able bodied basketball players; $1.7=$ Able bodied athletes; $2.54=$ Disabled non-practicing athletes. 


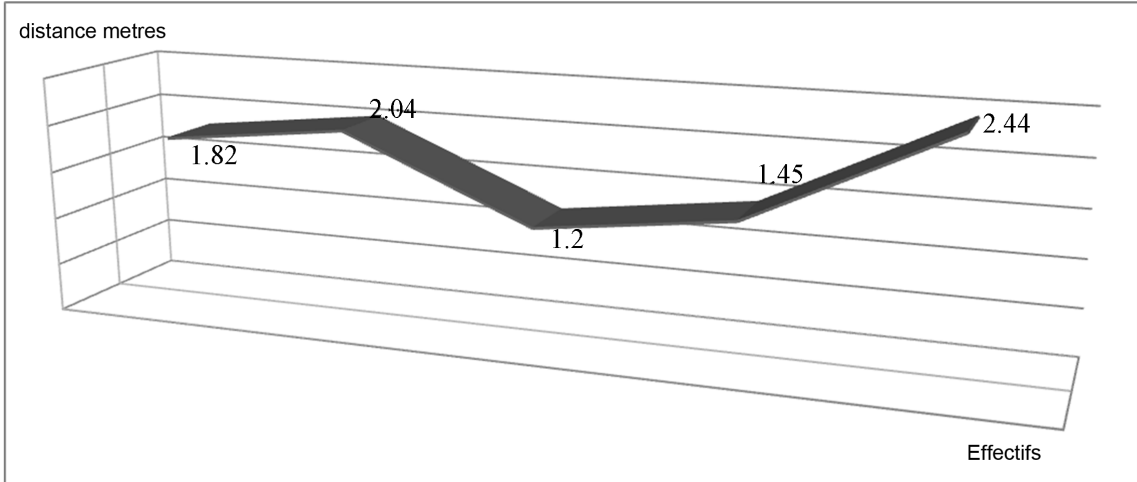

Figure 3. Average variation of the distance estimate of 10 meters. $1.82=$ Disabled basketball players; $2.04=$ Disabled athletes; $1.2=$ Able bodied basketball players; $1.45=$ Able bodied athletes; $2.44=$ Disabled non-practicing athletes.

We can therefore conclude that the practice of sport, in particular, basketball on wheelchair, develops effectively and in a significant way, the perception of distance for a motor-disabled subject.

The significant difference of physical self-esteem between the basketball players and the motor disabled athletes at the sub-scales health, adiposity, coordination, global physical satisfaction and the athletic skill, enables us to affirm that socio-motor games such as basketball develop better the self-esteem in the motor disabled. Moreover, we can even notice a trend effect of improving the perception of space and of time in the same subjects. On the other hand no effect was indexed about the auditory perception and paradoxically the non-athletes with motor disability have been as effective as the motor disabled basketball players and even more effective than the able bodied.

The statistical analyses of the questionnaire of Marsh show that the physical self-esteem in the motor disabled basketball players is always higher than that of the motor disabled athletes in the 11 sub-scales with the positive consequences of a regular exercise on a motor disabled person (Dias et al., 2009). As far as the motor disabled basketball players are concerned, their physical self-esteem is strongly influenced by their environment, the internal logic of the discipline, the atmosphere and the success of the team. Practicing basketball on wheelchair helps the players to accept their disabilities and provides them with self-confidence greater than that of the athletes.

How can we explain the reasons for better physical self-esteem and the effectiveness of temporal and spatial perceptions in the motor disabled basketball players?

Our explanation may be due to the following factors:

- Court dimensions:

The basketball court dimensions are much larger than the race lane or the throwing area for a disabled. This allows the basketball player, not only to have an area for greater interaction but also a wide field of vision influenced by the court dimensions, which makes his vision clearer and more precise. Therefore we deduce that the more the play space is important and the device or the inter- 
nal logic of the discipline seeks an important spatial moving, the more the individual is able to develop his perceptive abilities.

- The number of practitioners:

Every basketball team consists of 5 players, while during the athletic events in case of race test or throwing test, the practitioner responds in an isolated way. In basketball at the opposite the player is urged by relations of motor communications and counter communications: 4 relations of motor communication and 5 relations of motor counter-communication. The player has to continuously detect the information carried by the behaviour of the co-participants (opponents or partners), interpret and understand them. He has to seize relations and make new ones emerge out of them (Parlebas, 1986). The player's action depends on his way of perceiving his playing space and his co-partners participating into the action.

- The internal logic of the activity:

The goals (baskets) are suspended 3.05 meters above the ground, and in order to cover this area, the visual field of the basketball player is not only orientated frontwards in a horizontal level but also upwards in a vertical level. The visual field of the basketball players therefore covers one level more compared to the other sport disciplines. The team in possession of the ball has 24 seconds to shoot and the player has 3 seconds to dribble, pass the ball or shoot. This is likely to restrict the player to perceive space, to gather information and treat it as quickly as possible in order to respond effectively. The perception of the basketball player is not only the product of his visual system orientated horizontally and vertically, but also of his auditory system.

The auditory and visual perceptions are developed through the practical and gestural system that characterizes the team play. The 1st system is realized by the ball calls between the partners of the same team such as performing auditory signals destined to the ball carrier to mean their markdown and their ability to receive a pass having the function of performing a motor communication relationship.

The 2nd system is realized by signals produced by the game leader with his fingers to notify his partners of the number of the selected technical combination.

Playing basketball develops the perception of space and of self-esteem for a motor disabled subject, because as in any other team game motor communication plays a critical role for the practitioner, conditioning in this way the relationship of the practitioner and his space of interaction. In order to develop exchanges between two people, it is necessary that each partner decodes in a correct way what the other says the information being received in the form of a message (communication medium). The perception between player, space, partner and opponent is global. In this moment appears the inherent complexity of the human being: the other is perceived and recognized through his body in a face-to-face situation. The team is part of reduced groups, indicating in social psychology a group of people; a group or a team where everybody knows each 
other and a communication code.

On the other hand, the control of the motor execution in basketball on wheelchair directly influences the own perception of the disabled. This activity also provides him a possibility to access to confirmation of his personality and of his self-satisfaction which enables him gaining some strength of character. Thus, sport activity allows the motor disabled person to get a greater autonomy, a reconstruction of identity, a better integration into society, an improvement of one's self-perception and therefore an enhancement of one's self-esteem.

For a motor disabled playing basketball aims to synthesize, on the court, positive values such as the resistance to the opposition, the respect for the opponent and the group, no matter the injustices. Secondly, playing basketball on wheelchair also requires a great physical and psychological preparation that enhances the improvement of the self-esteem of a motor disabled person.

Finally, basketball is a team sport where it is essential to take into account the notions of competition, the need of team ability and motivation. Basketball is also a multidisciplinary practice that includes playing and situations rich with motor interactions and it would therefore be more appropriate for the development of perceptual abilities in athletes. Furthermore, it seemed important to us that sport practices confront the motor disabled with the reality making him aware of his limitations and capabilities through the game and through the rules of the social issue that they represent. The experience of the basketball players on wheelchair allowed each of them to reach a greater autonomy since this discipline requires not only great physical but psychological availability. This is likely to facilitate some improvement in the self-esteem of a motor disabled person. The development of self-esteem can act on the psycho-relational health in the motor disabled: it is because he recognizes himself in certain values that he is ready to meet and exchange with others who will not have the same opinion as him. In addition, the feeling of self-confidence allows trying new body learning in relation with a health development (Figure 4).

Indeed, the need for autonomy is the most important in explaining the behaviour. For example a young athlete in all disciplines, will be diligent in training for the pleasure of the contact sensation with the device or the environment as the gliding sensation brought by water for the swimmer or the contact of the ball with a basketball player's hand when dribbling or by the success of a pass to the partner, etc. This type of primarily kinaesthetic sensation will be strengthened and will increase during the training sessions. In this case, the motivation of the athlete turns to the satisfaction of well-being feeling. Moreover, according to Vallerand (2001), the context and the social and environmental factors are likely to facilitate self-determined motivation especially for wheelchair basketball players whose physical self-esteem was remarkably very high.

\section{Conclusion}

Our questioning on the importance of verbal and sign language communication 


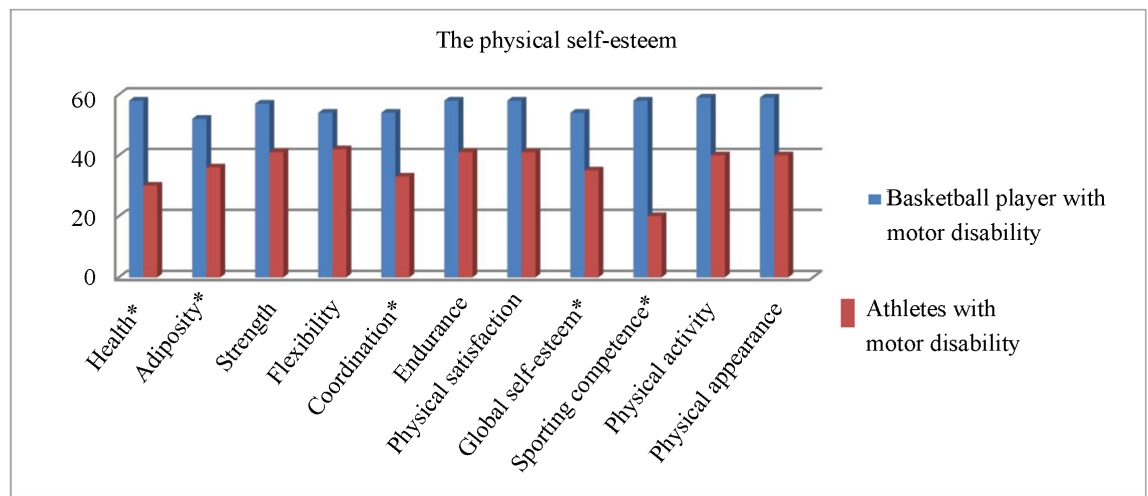

Figure 4. Histograms of basketball players and athletes with motor disability in the various subscales of the self-esteem measuring. The 11 scores of the PSDQ subscales are calculated by averaging the responses to the items designed to measure each scale ( the numbers of the items are placed in brackets and follow the name of each scale) after reversing the scores for the negatively formulated items (marked by the sign (-)). An analysis of the questionnaire results (PSDQ) enables us to notice in a quite remarkable way a general trend towards a better physical self-esteem, in the motor-disabled Basketball players at all subscales. This self-esteem is significantly better in the motor-disabled basketball players and it is located in the sub-scales: health $\left(\mathrm{ddl}=7, \mathrm{Kh}^{2}=17.86, P<.05\right)$, adiposity $\left(\mathrm{ddl}=5, \mathrm{Kh}^{2}=15.51, P<.010\right)$, coordination $\left(\mathrm{ddl}=5, \mathrm{Kh}^{2}=19.49, P<.010\right)$, global physical satisfaction ( $\left.\mathrm{ddl}=5, \mathrm{Kh}^{2}=15.51, P<.05\right)$ ), global self-esteem $\left(\mathrm{dl}=7 \mathrm{Kh}^{2}\right.$ $=15.95 P<.05)$ and sporting competence $\left(\mathrm{ddl}=5, \mathrm{Kh}^{2}=14.03, P<.03\right)$ (cf. the subscales endowed with asterisks). Nevertheless, no significant difference was noticed at the subscales: strength, flexibility, endurance, physical activity and physical appearance.

among the motor disabled practicing the APS and on the influence of practicing a team sport such as basketball on wheelchair over perception abilities has been demonstrated. We have proved that the more the court is reduced (as an interactional space), the more spatial and temporal perception is minimized. The practitioner finds himself sought by co-participants in the discipline which naturally helps maximizing his self-esteem. The practice of sport as socio-motor game develops better the perception than as in the form of psychomotor game in the disabled subject.

On the other hand, playing basketball on wheelchair plays a positive role in enabling the practitioners to develop their self-esteem. That's why the satisfaction of the basketball players of their physical appearance is higher than that of the motor disabled athletes. The physical self-esteem in the motor disabled basketball players is significantly high and is being developed thanks to the structure of the team as a cohesive group. This feeling builds a relation of co-motricity between players of the same team and reinforces the sense of value in the group. The experience and the general level of the team give players greater esteem of themselves and a better reconstruction of their personal identity. It also allows them a better integration into society, an improvement of their self-image and an acquisition of a greater autonomy.

In light of these results, we can propose the following suggestions to educational and sporting intervening parties for the benefit of the motor disabled subjects: 
- Encouraging the motor disabled to practice regularly a physical activity; this will be very important for their subjective well-being and health.

- Programming team sport for the disabled in order to allow them to reduce the impact of behavioural and emotional disorders.

One the of most important facts is undoubtedly that a sport environment providing security and support can help the practitioner to build his self-esteem by providing him with opportunities to develop his motor and psychomotor skills.

- Diversify the manipulation forms of the devices by different members of the body such as the arms, the head, etc...For basketball players, contact forms with the game instrument must be diversified through game situations that allow the practitioner to touch the ball with his whole body and not just by hands.

- Organize training situations in the form of reduced games: by reducing the play area and the number of practitioners, e.g. by the introduction of small game situations ( 3 against 3 on a reduced pitch).

- Expect during the athletic warm-up phase, various sporting activities in parallel and to avoid restricting sport exercises to the nature of the practiced sport by appealing to the collective game situations. This will effectively develop a social climate within the group as to develop the perceptual abilities in the practitioner and the perception of the self-esteem.

\section{References}

Bandura, A. (2003). Auto-efficacité. Le sentiment d'efficacité personnelle. [Self-Efficiency. The Sense of Personal Efficiency.] Paris: De Boeck.

Bilard, J. (1995). Reconstruction identitaire des blessés médullaires. Psychologie du sport: Questions actuelles. [Identity Rconstruction of the Medullary Injured, Psychology of Sport: Current Issues.] Paris: Editions EPS.

Blayak, N., \& Barbi, J. M. (2001). Medullary Injured, Sport Casualties: Incidence and Specificityof Psychological Factors in the Resumption of Sporting Activity. In C. Herisson, \& F. Ohanna (Eds.), Blessés médullaires accidentés du sport: In-cidence et spécificité des facteurs psychologiques dans la reprise de l'activité sportive (56-58).

Csikszentmihalyi, M. (2004). Living: Psychology of Happiness. Paris: Editions Robert Laffont.

Dias, C., Gerrnigon, C., \& Ninot, J. M. (2009). Competences Repository and Investment in the Practise of the Adapted Physical Activities for Recent Medullary Injured. Paris: INSEP.

Fox, K., \& Corbin, C. (1989). The Physical Self-Perception Profile: Development and Preliminary Validation. Journal of Sport \& Exercise Psychology, 11, 408-430. https://doi.org/10.1123/jsep.11.4.408

Jonveaux, T. R. (2010). The Appropriation of Temporality in Normal and Patholigical Aging. Doctoral Thesis, Nancy: University Nancy 2.

Legent, F. Bordure, P., Calais, C., \& Malard, O. (2002). Practical Audiology. Practical Manual of Hearing Tests. Paris: Edition Masson.

Lhermite, J. (1998). The Image of Our Body. Paris: L' Harmattan.

Marsh, H., \& Yeung, S. (1998). Top-Down, Bottom-Up and Horizontal Models: The Direction of Causality in Multidimential, Hierarchical Self-Concept Models. Journal of 
Personality and Social Psychology, 75, 509-527.

https://doi.org/10.1037/0022-3514.75.2.509

Nyabenda, A., Briart, C., Deggouj, N., \& Gersdorf, M. (2003). Rehabilitation and Physical Medicine Analysis (pp. 607-614). Brussels: Elsevier.

Parlebas, P. (1986). Elements of Sport Sociology. Sociology Collection. Paris: Presses Universitaires de France.

Schiano-Lomoriello, C., Cury, F., \& Dafonseca, D. (2005). Development and Validation of the Questionnaire of Approach and Avoidance in Physical and Sport Education (QAE-EPS). European Journal of Applied Psychology, 55, 85-98. https://doi.org/10.1016/j.erap.2004.06.004

Vallerand, R. J. (2001). A Hierarchical Model of Intrinsic and Extrinsic Motivation in Sport and Exercise. In G. C. Roberts (Ed.), Advances in Motivation in Sport and Exercise. Champaign, IL: Human Kinetics.

\section{Appendix}

The scores on PSD sub-scales.

\begin{tabular}{cc}
\hline Sub-scale & Corresponding Item \\
\hline Health & $1-$, 12-, 23-, 34-, 45-, 56-, 67-, 69 \\
Coordination & $2,13,24,36,46,57$ \\
Physical activity & $3,14,25,36,47,58$ \\
Adiposity & $4-, 15-, 26-, 37-, 48-, 59-$ \\
Sporting competence & $5,16,27,38,49,60$ \\
Physical appearance & $7,18,29,40,51,62$ \\
Strength & $8,19,30,41-, 52,63$ \\
Flexibility & $9,20,31-, 42,53,64$ \\
Endurance & $10,21,32,43,54,65$ \\
Global physical satisfaction & $6,17,28,39,50,61$ \\
Global self-esteem & $11,22-, 33-, 44-, 55,66,68-, 70$ \\
\hline
\end{tabular}


Submit or recommend next manuscript to SCIRP and we will provide best service for you:

Accepting pre-submission inquiries through Email, Facebook, LinkedIn, Twitter, etc. A wide selection of journals (inclusive of 9 subjects, more than 200 journals)

Providing 24-hour high-quality service

User-friendly online submission system

Fair and swift peer-review system

Efficient typesetting and proofreading procedure

Display of the result of downloads and visits, as well as the number of cited articles Maximum dissemination of your research work

Submit your manuscript at: http://papersubmission.scirp.org/

Or contact ape@scirp.org 